\title{
Study of Enterosorption Activity \\ of Carbon Sorbents Based \\ on Organosolvent Lignin of Fir Wood
}

\author{
Evgeniya V. Veprikova, Ivan P. Ivanov, \\ Nikolai V. Chesnokov and Boris N. Kuznetsov* \\ Institute of Chemistry and Chemical Technology SB RAS \\ FRC "Krasnoyarsk Science Center SB RAS" \\ 50/24 Akademgorodok, Krasnoyarsk, 660036, Russia
}

Received 27.03.2018, received in revised form 14.04.2018, accepted 27.05.2018

The sorption activity of carbon sorbents obtained from organosolvent lignin of fir wood with respect to methylene blue, vitamin $B_{12}$ and gelatin was studied. The influence of $\mathrm{pH}$ values of model solutions on the sorption of methylene blue and vitamin $B_{12}$ was established. The data on the kinetics of sorption of these marker substances by carbon sorbents from lignin of fir woodwas presented. It was found that the ability of the studied sorbents to sorb the marker substancesexceeds the industrial activated carbons usedfor medical purposes.

Keywords: fir wood, lignin, sorption, methylene blue, vitamin $B_{12}$, gelatin.

Citation: Veprikova E.V., Ivanov I.P., Chesnokov N.V., Kuznetsov B.N. Study of enterosorption activity of carbon sorbents based on organosolvent lignin of fir wood, J. Sib. Fed. Univ. Chem., 2018, 11(2), 249-261. DOI: 10.17516/1998-2836-0072.

(c) Siberian Federal University. All rights reserved

* Corresponding author E-mail address: veprikova2@mail.ru 


\title{
Изучение энтеросорбционной активности \\ углеродных сорбентов
}

на основе органосольвентного лигнина древесины пихты

\author{
Е.В. Веприкова, И.П. Иванов, \\ Н.В. Чесноков, Б.Н. Кузнецов \\ Институт химии и химической технологии СО РАН \\ ФИЦ «Красноярский научный иентр СО РАН» \\ Россия, 660036, Красноярск, Академгородок, 50/24
}

Изучена сорбционная активность углеродных сорбентов, полученных из органосольвентного лигнина древесины пихты, в отношении метиленового синего, витамина $B_{12}$ и желатина. Выявлено влияние значений рН модельных растворов на сорбиию метиленового синего и витамина $B_{12}$. Приведены данные о кинетике сорбции этих маркерных веществ углеродными сорбентами из лигнина древесины пихты. Установлено, что по способности сорбировать маркерные вещества исследуемые сорбенты превосходят промышленные активированные угли медицинского назначения.

Ключевые слова: древесина пихты, лигнин, сорбция, метиленовый синий, витамин $B_{12}$, желатин.

\section{Введение}

Актуальной областью применения сорбентов на основе лигноцеллюлозного сырья является энтеросорбция, используемая в медицине и ветеринарии для удаления токсинов различной природы $[1,2]$. В условиях увеличения техногенной нагрузки на окружающую среду применение энтеросорбентов позволяет восстанавливать, поддерживать и регулировать нормальное функционирование организмов людей и животных.

Расширение масштабов применения сорбентов медицинского назначения диктует необходимость поиска новых видов доступного сырья и разработки новых эффективных технологий для их получения. В этом отношении древесные отходы наиболее распространенное сырье на территории России. Вовлечение в производство активных углей дешевого регионального возобновляемого сырья дает возможность существенно снизить их себестоимость, что увеличивает перспективы их применения для медицины и ветеринарии $[3,4]$.

Получение энтеросорбентов из материалов органического происхождения (древесина, лигнин, торф и др.), не прошедших стадию термической обработки, ограничивает их применение значительным содержанием пылевидной фракции, минеральных веществ и органическими соединеними, которые способны проявлять токсичные свойства $[5,6]$. Перспективным сырьем, позволяющим устранить или минимизировать содержание таких веществ, могут являться лигнины, выделенные из отходов растительной биомассы [7-9].

Активные угли, традиционно получаемые методом физической парогазовой активации древесного сырья (в основном древесины березы), широко используются в процессах энте- 
росорбции $[1,10]$. Однако накопленный опыт позволяет говорить о возможности получения углеродных сорбентов из растительной биомассы и ее компонентов с использованием методов химической активации $[3,11]$. Химические методы активации с использованием гидроксидов щелочных металлов (натрия, калия) дают возможность получать углеродные материалы с высокоразвитой пористой структурой. Главным преимуществом химических методов активации по сравнению с физическими служит то, что процесс осуществляется в объеме активируемого материала и позволяет варьировать параметрами процесса для получения сорбентов с требуемой пористой структурой [12].

В работе [9] разработаны условия, позволяющие получать высокопористые углеродные материалы на основе лигнина древесины пихты методом термохимической активации при $800{ }^{\circ} \mathrm{C}$ в присутствии гидроксида калия. Установленная возможность регулирования параметрами пористой структуры в процессе получения позволяет целенаправленно определять направления применения разработанных материалов для решения конкретных задач сорбционной очистки.

Возможность применения вновь разработанных углеродных сорбентов в медицинских целях зависит от его способности сорбировать экзо- и эндотоксины различной природы. В практике определения сорбционных свойств энтеросорбентов используются маркерные вещества, моделирующие различные классы токсинов: метиленовый синий моделирует токсины с массой до 500 Д; витамин $\mathrm{B}_{12}$ моделирует токсины массой 500-1500 Д; желатин, моделирует токсины белковой природы [13]. Кроме того, по сорбции этих маркерных веществ можно судить об эффективности новых сорбентов для удаления красителей, гуминовых веществ, загрязнений белковой природы из стоков различных производств. Поэтому изучение сорбционных свойств нанопористых углеродных сорбентов, полученных из лигнина древесины пихты, является актуальной задачей и позволит определить наиболее перспективные области его применения.

Цель работы заключалась в изучении сорбционной активности углеродных сорбентов, полученных из лигнина древесины пихты методом термощелочной активации при $800{ }^{\circ} \mathrm{C}$ в присутствии гидроксида калия, в отношении метиленового синего, витамина $\mathrm{B}_{12}$ и желатина.

\section{Экспериментальная часть}

Углеродные сорбенты были получены на основе органосольвентного лигнина древесины пихты согласно методике работы [9]. Условия получения сорбентов приведены в табл. 1.

Для проведения исследований по определению сорбционной активности образцы углеродных сорбентов измельчали до размера частиц менее 0,25 мм. Определение сорбционной активности проводили по маркерным веществам с разной молекулярной массой в соответствии с методикой работы [14]. Концентрация маркеров в модельных растворах равнялась $0,15,0,01$ и $0,60 \%$ для метиленового синего, витамина $\mathrm{B}_{12}$ и желатина соответственно. Навеска сорбента для анализа составляла 80 мг, объем раствора маркера - 10 мл. Растворы маркерных веществ содержали фоновый электролит $\mathrm{NaCl}$ в количестве 0,9 мас. \%. Сорбцию изучали при значениях $\mathrm{pH}$ растворов маркерных веществ - 2,0, 5,4 и 8,0. Значения $\mathrm{pH} 2,0$ и 8,0, моделирующие со- 
Таблица 1. Условия получения углеродных сорбентов из органосольвентного лигнина древесины пихты Table 1. Conditions of obtaining of carbon sorbents from organosolvent lignin of fir wood

\begin{tabular}{|c|l|}
\hline Образец сорбента & \multicolumn{1}{|c|}{ Условия получения } \\
\hline УС-1 & Скорость нагрева 1 \%мин, конечная температура $800^{\circ} \mathrm{C}$, выдержка при $800{ }^{\circ} \mathrm{C} 1$ ч \\
\hline УС-5 & Скорость нагрева 5 \%мин, конечная температура $800{ }^{\circ} \mathrm{C}$ \\
\hline УС-10 & Скорость нагрева $10 \%$ мин, конечная температура $800{ }^{\circ} \mathrm{C}, 1$ ч, аргон \\
\hline УС-20 & $\begin{array}{l}\text { Скорость нагрева } 20 \% \text { мин, конечная температура } 800^{\circ} \mathrm{C}, \text { выдержка при } 800^{\circ} \mathrm{C} \\
1 \text { ч, аргон }\end{array}$ \\
\hline УС-40 & Скорость нагрева 40 \%мин, конечная температура $800^{\circ} \mathrm{C}$ \\
\hline
\end{tabular}

стояние среды желудка и кишечника, устанавливали с помощью $\mathrm{HCl}$ и $\mathrm{NaOH}$ соответственно. Растворы с рН 5,4 получали растворением маркеров в дистиллированной воде, кислотность которой составляла 5,4 .

Изотермы сорбции метиленового синего и витамина $\mathrm{B}_{12}$ получали из модельных растворов с концентрацией 1500 и 300 мг/л (pH 5,4), масса навесок сорбента варьировалась от 10 до 200 мГ при прочих равных условиях. Значения максимальной сорбции маркеров были получены при использовании навески сорбента, равной 10 мг.

При изучении кинетики сорбции МС и $\mathrm{B}_{12}$ продолжительность контакта сорбентов с модельными растворами маркерных веществ варьировала от 1 до 120 мин. В остальных экспериментах продолжительность сорбции составляла 1 ч. Процесс проводили при перемешивании на лабораторном приборе марки АВУ-6 с 120 колеб/мин.

Промышленные образцы угля активированного, выпускаемого ЗАО «Медисорб» (г. Пермь, Р.72.270.3) и ЗАО «Производственная фармацевтическая компания Обновление» (г. Новосибирск, ЛП-000178) (соответственно образец УА-Н и образец УА-П), были выбраны в качестве образцов сравнения. Их измельчали до размера частиц менее 0,25 мм и отмывали горячей водой от вспомогательных веществ. Определение их сорбционной активности проводили аналогично с исследуемыми образцами сорбентов.

По уравнениям изотерм сорбции Ленгмюра (1) и Фрейндлиха (2), приведенным к линейному виду, вычисляли соответствующие коэффициенты для процессов сорбции маркерных веществ:

$$
\begin{aligned}
& A^{-1}=\left(A_{\infty} K_{L}\right)^{-1} C_{p}^{-1}+A_{\infty}^{-1}, \\
& \log A=\log K_{F}+n^{-1} \log C_{p},
\end{aligned}
$$

где $\mathrm{A}$ - сорбция маркера, мг/г; $\mathrm{A}_{\infty}$ - предельная сорбция, мг/г; $\mathrm{C}_{\mathrm{p}}$ - равновесная концентрация маркера, мг/л; $\mathrm{K}_{\mathrm{L}}$ - константа уравнения Ленгмюра; $\mathrm{K}_{\mathrm{F}}$ - константа уравнения Фрейндлиха; $\mathrm{n}$ - константа интенсивности сорбции в уравнении Фрейндлиха.

Определение характеристик пористой структуры углеродных сорбентов, полученных из лигнина пихты, производили по сорбции $\mathrm{N}_{2}$ при 77К с использованием анализатора удельной поверхности и микропористости ASAP 2020 (Micromeritics) по методике, приведенной в работе [9]. 


\section{Результаты и обсуждение}

Сорбционная емкость исследованных углеродных сорбентов, полученных при различных условиях из органосольвентного лигнина древесины пихты, в сравнении с промышленными активными углями медицинского назначения приведена в табл. 2.

Приведенные в табл. 2 данные свидетельствуют о том, что углеродные сорбенты из лигнина древесины пихты характеризуются развитой удельной поверхностью и пористостью, что обуславливает высокие значения их сорбционной емкости по метиленовому синему. По способности сорбировать этот маркер исследуемые сорбенты превосходят образцы сравнения. Следует отметить, что образцы УС-10 и УС-40 практически полностью сорбируют МС из модельного раствора - максимально возможная сорбция равна 187,5 мг/г.

Наблюдаемое различие в сорбционной емкости по МС углеродных сорбентов из лигнина древесины пихты и образцов сравнения коррелирует с различными значениями удельной поверхности и суммарного объема пор (табл. 2). Очевидно, более развитая пористая структура образцов УС обуславливает высокие значения их сорбционной емкости по данному маркеру.

Сопоставление значений сорбции маркерного вещества и размеров молекул метиленового синего (1,60x0,84x0,47 нм [15]) свидетельствует также о высокой степени доступности пористой структуры исследуемых сорбентов для его молекул. Эти данные хорошо соотносятся со средним размером пор исследуемых сорбентов, полученных на основе лигнина пихты. Для промышленных активных углей сорбция МС характеризуется более низкими значениями. Данный факт может быть объяснен различием развития пористости в процессах физической и химической активации органического сырья. При физической активации развитие пористой структуры происходит, главным образом, за счет обгаранативных пор в процессе окисления, тогда как при химической активации реализуется процесс объемного формирования пористой структуры за счет проникновения гидроксидов щелочных металлов вглубь материала по нативным порам и образования новых пор.

Таблица 2. Сорбционная емкость углеродных сорбентов из органосольвентного лигнина древесины пихты (рН модельных растворов 5,4, фоновый электролит - 0,9 \% $\mathrm{NaCl}$ )

Table 2. Sorption capacity of carbon sorbents from organosolvent lignin of fir wood ( $\mathrm{pH}$ of model solutions is 5,4, stock electrolyte $-0,9 \% \mathrm{NaCl}$ )

\begin{tabular}{|c|c|c|c|c|c|c|c|c|}
\hline \multirow{2}{*}{ Образец } & \multirow{2}{*}{$\mathrm{S}_{\text {Бэт }}, \mathrm{M}^{2} / \Gamma$} & \multirow{2}{*}{$\mathrm{V}_{\text {общ }}, \mathrm{CM}^{3} / \Gamma$} & \multirow{2}{*}{$\mathrm{V}_{\text {мезо }}, \mathrm{cm}^{3} / \Gamma$} & \multirow{2}{*}{$\begin{array}{c}\text { Доля } \\
\text { мезопор, } \\
\text { отн. \% }\end{array}$} & \multirow{2}{*}{$\begin{array}{l}\text { Размер } \\
\text { пор, нм }\end{array}$} & \multicolumn{3}{|c|}{ Сорбция, мг/Г } \\
\hline & & & & & & $\mathrm{MC}$ & $\mathrm{B}_{12}$ & Желатин \\
\hline $\mathrm{YC}-1$ & 2191 & 1,04 & 0,08 & 7,7 & 1,88 & 183,4 & 8,0 & Не сорбирует \\
\hline $\mathrm{YC}-5$ & 2788 & 1,29 & 0,1 & 7,8 & 1,89 & 186,3 & 12,5 & 5,7 \\
\hline УC-10 & 2679 & 1,31 & 0,13 & 9,9 & 1,92 & 187,4 & 12,5 & Не сорбирует \\
\hline УC-20 & 2921 & 1,65 & 0,40 & 24,2 & 2,25 & 186,9 & 12,5 & Не сорбирует \\
\hline УC-40 & 3157 & 1,92 & 0,65 & 33,8 & 2,43 & 187,4 & 12,5 & Не сорбирует \\
\hline УA-H* & 638 & 0,39 & 0,14 & 35,9 & 2,41 & 161,1 & 4,2 & Не сорбирует \\
\hline УА-П* & 583 & 0,38 & 0,20 & 51,3 & 2,64 & 145,3 & 8,1 & Не сорбирует \\
\hline
\end{tabular}

* Образцы сравнения: УА-Н - уголь активированный, г. Новосибирск; УА-П - уголь активированный, г. Пермь; $\mathrm{S}_{\text {Бэт }}$ - удельная поверхность, $\mathrm{V}_{\text {общ, }}$ - суммарный объем микро- и мезопор, $\mathrm{V}_{\text {мезо }}$ - объем мезопор, $\mathrm{MC}$ - метиленовый синий, $\mathrm{B}_{12}$ - витамин $\mathrm{B}_{12}$.

$$
-253-
$$


По способности сорбировать витамин $\mathrm{B}_{12}$ можно выделить образец УС-1, который уступает остальным исследуемым сорбентам и находится на уровне промышленного активного угля УА-Н (табл. 2). Данный факт можно объяснить более низким значением суммарного объема пор и доли мезопор в пористой структуре сорбента УС-1 по сравнению с другими образцами. Очевидно, что для сорбции витамина $\mathrm{B}_{12}$, молекулы которого имеют более разветвленную структуру по сравнению с молекулами метиленового синего, значимым является не общий объем пор сорбента, а наличие в его структуре пор, доступных для молекул маркерного вещества. Известно, что для $\mathrm{B}_{12}$, объем молекул которого составляет $2980 \AA^{3}$, доступны поры с радиусом от 0,85 до $1,2-1,6$ нм $[15,16]$. Можно предположить, что доля пор такого размера в структуре сорбента УС-1 меньше по сравнению с другими исследованными сорбентами, но близка или превышает этот показатель для промышленных активных углей.

Изучение влияния пористой структуры углеродных сорбентов из лигнина пихты при интенсивности нагрева $1-40{ }^{\circ} \mathrm{C} /$ мин на сорбционную емкость по МС и $\mathrm{B}_{12}$ показало (табл. 1 , рис. 1), что она имеет прямую корреляцию с объемом образующихся мезопор. При этом, как и в случае с влиянием интенсивности нагрева, наиболее интенсивное увеличение сорбционной емкости происходит на начальном этапе, когда суммарный объем возрастает от 1,04 до $1,29 \mathrm{~cm}^{3} / \Gamma$, а объем мезопор - от 0,08 до $0,1 \mathrm{~cm}^{3} / \Gamma$. Дальнейшее повышение объема мезопор в исследованных условиях определения сорбционной емкости углеродных сорбентов из лигнина пихты при рН 5,4 сопровождается достижением предельных значений на уровне 187,5 и 12,5 мг/г по МС и $\mathrm{B}_{12}$ соответственно.

Сравнение сорбционной емкости исследуемых образцов углеродных сорбентов, полученных из лигнина древесины пихты, и промышленных активных углей, полученных из древесины березы, показывает, что исследуемые образцы обладают более высокой емкостью по МС (в $1,6-2,9$ раза) и $\mathrm{B}_{12}$ (в $1,5-3,0$ раза).

Важно отметить, что достигаемая для ряда образцов УС сорбционная емкость по витамину $\mathrm{B}_{12}(12,5$ мг/г) представляет собой максимальное значение для 0,01\%-го модельного раствора (табл. 2). На примере УС-2 было установлено, что при повышении концентрации раствора

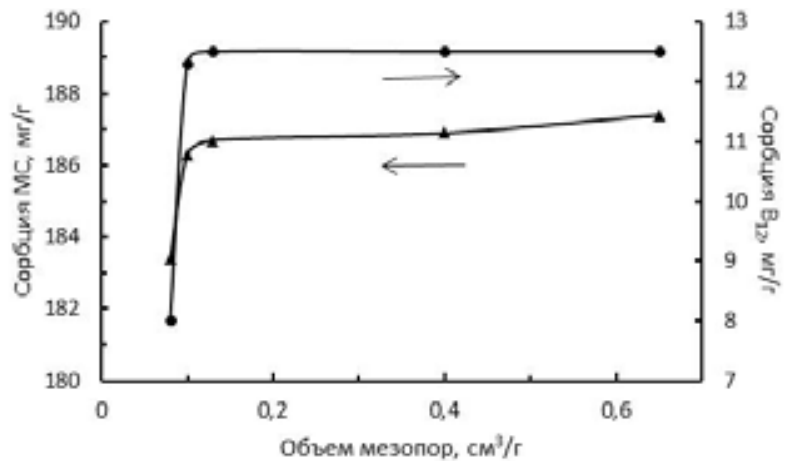

Рис. 1. Зависимость сорбционной емкости по $\mathrm{MC}$ и $\mathrm{B}_{12}$ при $\mathrm{pH} 5,4$ от объема мезопор углеродных сорбентов из лигнина пихты

Fig. 1. Dependence of the sorption capacity for $\mathrm{MB}$ and $\mathrm{B}_{12}$ at $\mathrm{pH} 5,4$ on volume of the mesopores of carbon sorbents from fir wood lignin 
витамина $\mathrm{B}_{12}$ до 0,02 \% значение сорбционной емкости возрастает до 17,6 мг/г. Это позволяет предположить возможность использования сорбентов, полученных на основе лигнина древесины пихты, для эффективного удаления среднемолекулярных токсинов различной природы и необходимость проведения дальнейших исследований в данном направлении.

Данные табл. 2 показывают, что изученные углеродные сорбенты из лигнина древесины пихты, как и образцы сравнения, не способны сорбировать маркер белковых токсинов желатин. Исключение составляет УС-5, сорбирующий не более 5,7 мг/г желатина при рН 5,4. Однако при рН 2,0 и 8,0, моделирующих состояние желудка и кишечника, сорбции данного маркера не происходит. Очевидно, поры углеродных сорбентов из лигнина пихты недоступны для макромолекул желатина, состоящих из трех полипептидных $\alpha$-цепей со средней длиной около 1,7 нм (диаметр спирали около 2 нм) [17]. Неспособность активных углей сорбировать желатин известна [14], однако это не ограничивает их эффективное применение в медицинской практике для удаления экзо- и эндотоксинов разной природы $[1,10]$.

Как видно из данных, представленных на рис. 1 и в табл. 2, некоторые углеродные сорбенты из лигнина характеризуются способностью практически полностью поглощать метиленовый синий из модельных растворов, а $\mathrm{B}_{12}$ - все, за исключением УС-1. Поэтому интересно оценить максимальную сорбционную емкость сорбентов по выбранным маркерным веществам.

На рис. 2 приведены изотермы сорбции метиленового синего и витамина $\mathrm{B}_{12}$ углеродными сорбентами из лигнина УС-1 и УС-5, показывающие их высокую сорбционную активность в широком интервале концентраций маркерных веществ. Видно, что поглощение маркерных веществ этими сорбентами отличается по величинам сорбционной емкости и по характеру изотерм сорбции.

Так, сорбция обоих маркеров сорбентом УС-1 описывается изотермами ленгмюровского типа. В соответствии с классификацией БЭТ эти изотермы относятся к I типу, что свидетельствует о монослойной сорбции данного маркера. Изотерма сорбции витамина $\mathrm{B}_{12}$, полученная для сорбента УС-5, с высокой достоверностью аппроксимируется уравнением Ленгмюра
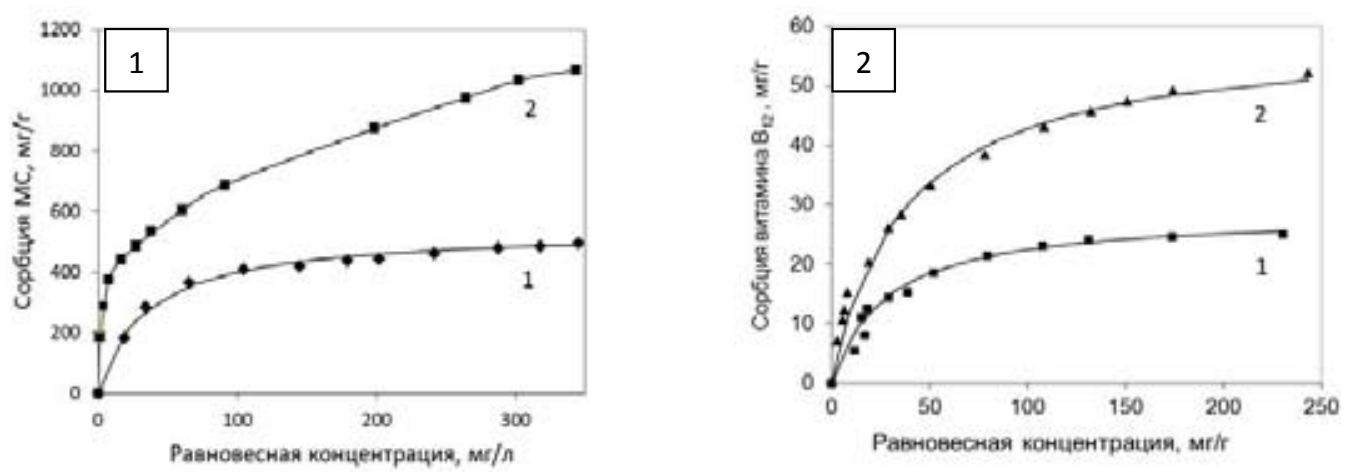

Рис. 2. Изотермы сорбции метиленового синего (1) и витамина $\mathrm{B}_{12}(2)$ на углеродных сорбентах из лигнина древесины пихты: 1 - сорбент УС-1; 2 - сорбент УС-5. Точки - экспериментальные значения, линии расчетные кривые

Fig. 2. Isotherms of sorption of methylene blue (1) and vitamin $B_{12}(2)$ on thecarbon sorbents from fir wood lignin: 1 - sorbent YC -1; 2 - sorbent YC-5. Points - the experimental dates, lines - the calculated curves 
(рис. 2-2, табл. 3). Однако это уравнение неприменимо для описания процесса сорбции метиленового синего, поскольку расчетное значение предельной сорбции в 1,6 раза меньше максимально достигнутого в эксперименте (рис. 2-2 и табл. 3). На изотерме сорбции этого маркера наблюдается крутой подъем в области низких равновесных концентраций до 7,5 мг/г. Такой характер сорбции обусловлен более развитой удельной поверхностью сорбента УС-2 и большим объемом пор. Подобные изотермы предложено относить к типу Н2 по классификации Гильса (изотермы с высоким сродством) [18].

Было установлено, что для УС-5 сорбция метиленового синего достоверно аппроксимируется уравнением Фрейндлиха во всем интервале исследованных равновесных концентраций (рис. 2-1). Параметры уравнения составили: $\mathrm{n}=3.35, \mathrm{~K}=184.57, \mathrm{R}^{2}=0.991$.

Данные табл. 4 показывают, что для сорбентов из лигнина характерна высокая сорбционная активность по метиленовому синему. По максимально достигнутым в эксперименте значениям сорбции они существенно превосходят образцы сравнения.

Таблица 3. Параметры изотермы Ленгмюра для сорбции метиленового синего и витамина В 12 углеродными сорбентами из лигнина древесины пихты

Table 3. Parameters of Lengmuir isotherm for sorption of methylene blueand vitamin $\mathrm{B}_{12}$ by carbon sorbents from fir wood lignin

\begin{tabular}{|c|c|c|c|}
\hline \multirow{2}{*}{ Сорбент } & \multicolumn{3}{|c|}{ Параметры изотермы } \\
\cline { 2 - 4 } & $\mathrm{A}_{\infty}$, мг/г & $\mathrm{K}_{\mathrm{L}}$ & $\mathrm{R}^{2}$ \\
\hline \multicolumn{4}{|c|}{ Сорбция метиленового синего } \\
\hline УС-1 & 540,10 & 0,0285 & 0,988 \\
\hline УС-5 & 662,65 & 0,377 & 0,839 \\
\hline \multicolumn{4}{|c|}{ Сорбция витамина $\mathrm{B}_{12}$} \\
\hline УС-1 & 28,64 & 0,0362 & 0,987 \\
\hline УС-5 & 58,82 & 0,0267 & 0,992 \\
\hline
\end{tabular}

Примечание. $\mathrm{A}_{\max }$ - экспериментальная максимальная сорбция; $\mathrm{R}^{2}$ - коэффициент аппроксимации.

Таблица 4. Максимальная сорбционная емкость углеродных сорбентов из лигнина древесины пихты (рН модельных растворов 5,4, фоновый электролит - $0,9 \% \mathrm{NaCl}$ )

Table 4. Maximal sorption capacity ofcarbon sorbents from fir wood lignin ( $\mathrm{pH}$ of model solutions is 5,4, stock electrolyte $-0,9 \% \mathrm{NaCl}$ )

\begin{tabular}{|c|c|c|}
\hline Образец & Сорбция МС, мг/г & Сорбция $\mathrm{B}_{12}$, мг/Г \\
\hline УС-1 & 496,39 & 25,05 \\
\hline УС-5 & 1066,96 & 52,24 \\
\hline УС-10 & 1078,39 & 65,58 \\
\hline УС-20 & 933,35 & 142,17 \\
\hline УС-40 & 1074,39 & 188,68 \\
\hline Уголь активированный, г. Новосибирск* (УАН) & 256,16 & 61,53 \\
\hline Уголь активированный, г. Пермь* (УАП) & 243,78 & 49,77 \\
\hline
\end{tabular}

* Образцы сравнения; МС - метиленовый синий, $\mathrm{B}_{12}$ - витамин $\mathrm{B}_{12}$. 
Из представленных в табл. 1 и 4 данных видно, что способность сорбировать витамин $\mathrm{B}_{12}$ зависит от условий получения сорбентов в большей степени, чем способность к сорбции метиленового синего.

Целесообразность применения вновь разработанных сорбентов в области энтеросорбции определяется не только их высокой активностью в отношении общепринятых маркерных веществ. Сорбенты, предназначенные для этой цели, должны также обладать высокой интенсивностью поглощения маркеров различной природы [10]. Поэтому на примере сорбентов УС-1 и УС-2, имеющих некоторые отличия по своей сорбционной активности, была изучена кинетика сорбции маркерных веществ из модельных растворов с $\mathrm{pH} 2,0$ и 8,0 в присутствии фонового электролита $(0,9 \% \mathrm{NaCl})$, моделирующих условия сред желудка и кишечника соответственно.

Приведенные на рис. 3 и 4 зависимости показывают, что при рН 8,0 метиленовый синий сорбируется быстрее, чем из раствора с $\mathrm{pH}$ 2,0. Сорбционное равновесие в щелочном растворе маркера устанавливается через 45 мин для УС-1 и через 10 мин для УС-2. При рН 2,0 сорбционное равновесие устанавливается в течение более длительного времени - через 60 мин для УС-1 и через 45 мин для УС-5.

Независимо от исследованных значений $\mathrm{pH}$ модельных растворов УС-5 быстро сорбирует метиленовый синий - за 5 мин сорбция маркера достигает 97,3 и 99,9 \% (от значений равновесной сорбции) при рН 2,0 и 8,0 соответственно. В аналогичных условиях УС-1 сорбирует маркер в меньших количествах - 87,5 и 97,7 \% соответственно.

Следует отметить, что в процессе сорбции из кислого раствора сорбент УС-1 поглощает маркер в меньшем количестве по сравнению с сорбцией из щелочного раствора. Основное различие в величинах сорбционной емкости этого сорбента наблюдается в течение 45 мин, а для сорбента УС-5 - в течение 30 мин (рис. 3 и 4). Установленное влияние рН на сорбцию маркера свидетельствует о необходимости учитывать вклад электростатических взаимодействий. Поскольку метиленовый синий является типичным катионным красителем, его электростатиче-

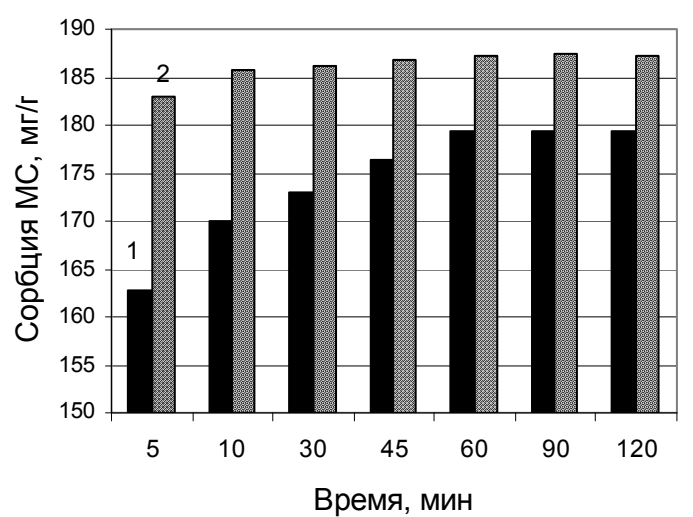

Рис. 3. Сорбция метиленового синего (МС) сорбентом УС-1 из модельных растворов при $\mathrm{pH}$ 2,0 (1) и рН 8,0 (2)

Fig. 3. Sorption of methylene blue (MC) by sorbent YC-1 from model solutions at $\mathrm{pH}$ 2,0 (1) and $\mathrm{pH} 8,0$ (2)

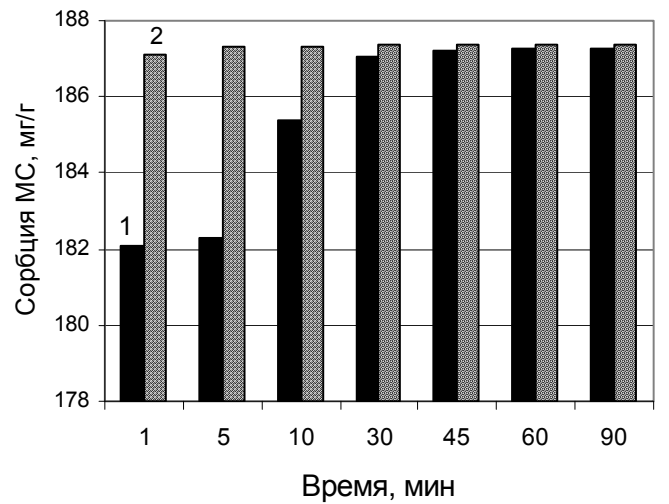

Рис. 4. Сорбция метиленового синего (МC) сорбентом УС-5 из модельных растворов при $\mathrm{pH}$ 2,0 (1) и $\mathrm{pH} 8,0$ (2)

Fig. 4. Sorption of methylene blue (MC) by sorbent YC-5 from model solutions at $\mathrm{pH} 2,0$ (1) and $\mathrm{pH} 8,0$ (2) 
ское отталкивание от протонированной поверхности сорбентов при $\mathrm{pH} 2,0$ затрудняет сорбцию [18]. Очевидно, что для УС-5 в период времени от 30 до 90 мин отрицательное влияние такого взаимодействия минимизируется в отличие от сорбента УС-1. Для последнего наблюдаемый негативный эффект более выражен, несмотря на присутствие в растворе фонового электролита.

Следует отметить, что исследуемые углеродные сорбенты из лигнина древесины пихты характеризуются практически равными значениями равновесной сорбционной емкости по метиленовому синему, достигаемыми из растворов с $\mathrm{pH}$ 8,0 (табл. 5). Сравнение этих значений с данными табл. 2 показывает, что изменение $\mathrm{pH}$ растворов маркера от 5,4 до 8,0 не влияет на сорбционную емкость УС-5, но приводит к увеличению этого значения для УС-1. При этом способность УС-2 сорбировать метиленовый синий не меняется с повышением кислотности до 2,0 . В то время как для сорбента УС-1 наблюдается незначительное уменьшение сорбции - на $2,3 \%$ (рис. 3 и 4 , табл. 2 и 5).

В случае сорбции витамина $\mathrm{B}_{12}$ наблюдается противоположное влияние $\mathrm{pH}$ растворов при поглощении исследуемыми сорбентами (табл. 5). Для исследованных сорбентов УС-1 и УС-5 и образцов сравнения значение равновесной сорбции при понижении кислотности раствора маркера от 2,0 до 8,0 сопровождается уменьшением сорбционной емкости по витамину $\mathrm{B}_{12}$. Можно предположить, что в щелочных растворах эффекты электростатического взаимодействия молекул маркерного вещества с поверхностью сорбента затрудняют его сорбцию [18].

Было установлено, что витамин $\mathrm{B}_{12}$ сорбируется существенно медленнее по сравнению с метиленовым синим. Время достижения сорбционного равновесия не зависит от $\mathrm{pH}$ растворов маркера и составляет 60 мин для УС-1 и 50 мин для УС-5 (рис. 5 и 6).

Однако из растворов с $\mathrm{pH}$ 2,0 через 5 мин сорбент УС-5 поглощает до 58 \% маркерного вещества, а УС-1 только 41,8. Из щелочного раствора маркер сорбируется в меньших количествах (33,9 и 42,0 \% от значений равновесной сорбции) соответственно.

Характер влияния $\mathrm{pH}$ растворов на сорбцию маркерных веществ свидетельствует о большой эффективности исследуемых сорбентов при удалении маркерных веществ массой до 500 Д в условиях, моделирующих среду кишечника, а с массой 500-1500 Д- в условиях, моделирующих среду желудка.

Таблица 5. Сорбция метиленового синего (МС) и витамина $\mathrm{B}_{12}$ сорбентами из лигнина древесины пихты и промышленными активными углями из растворов при различных значениях $\mathrm{pH}$

Table 5. Sorption of methylene blue (MC) and vitamin $\mathrm{B}_{12}$ by carbon sorbents from fir wood ligninand commercial active carbon from solutions at different $\mathrm{pH}$ values

\begin{tabular}{|c|c|c|c|c|}
\hline \multirow{2}{*}{ Сорбент } & \multicolumn{2}{|c|}{ Сорбция МС, мг/г } & \multicolumn{2}{c|}{ Сорбция $\mathrm{B}_{12}, \mathrm{мг} /$ г } \\
\cline { 2 - 5 } & $\mathrm{pH} \mathrm{2,0}$ & $\mathrm{pH} 8,0$ & $\mathrm{pH} \mathrm{2,0}$ & $\mathrm{pH} \mathrm{8,0}$ \\
\hline УС-1 & 179,3 & 187,3 & 7,9 & 6,3 \\
\hline УС-5 & 187,3 & 187,4 & 12,5 & 11,4 \\
\hline УА-Н & 153,7 & 162,2 & 4,3 & 2,9 \\
\hline УА-П & 140,5 & 146,3 & 7,9 & 6,1 \\
\hline
\end{tabular}

Равновесная сорбция маркеров в присутствии фонового электролита $-0,9 \% \mathrm{NaCl}$. 


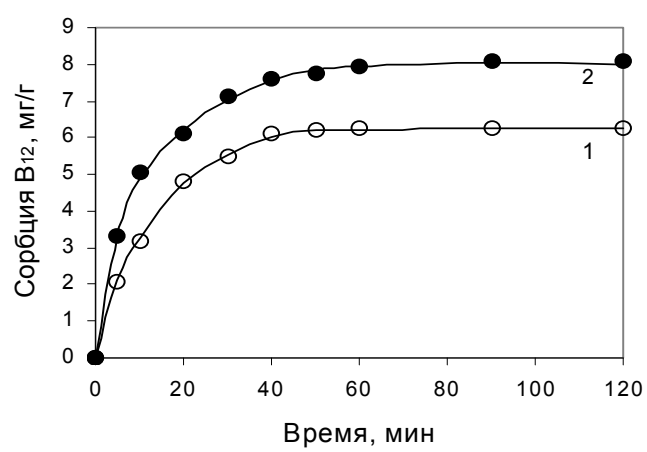

Рис. 5. Сорбция витамина $\mathrm{B}_{12}$ сорбентом УС-1 из модельных растворов при $\mathrm{pH} 8,0$ (1) и $\mathrm{pH} 2,0$ (2)

Fig. 5. Sorption of vitamin $\mathrm{B}_{12}$ by sorbent $\mathrm{YC}-1$ from model solutions at $\mathrm{pH} 8,0$ (1) and $\mathrm{pH} 2,0$ (2)

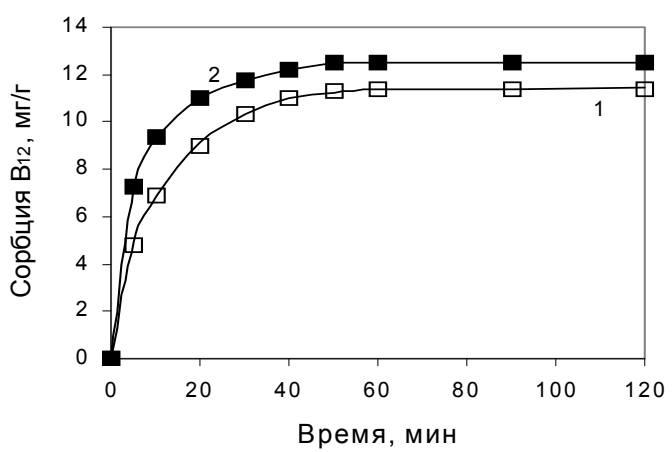

Рис. 6. Сорбция витамина $\mathrm{B}_{12}$ сорбентом УС-5 из модельных растворов при рН 8,0 (1) и $\mathrm{pH} 2,0$ (1)

Fig. 6. Sorption of vitamin $\mathrm{B}_{12}$ by sorbent $\mathrm{YC}-5$ from model solutions at $\mathrm{pH} 8,0$ (1) and $\mathrm{pH} 2,0$ (2)

\section{Заключение}

Исследования показали, что углеродные сорбенты, полученные при различных условиях термощелочной активации органосольветного лигнина древесины пихты, характеризуются высокой сорбционной активностью в отношении метиленового синего и витамина $\mathrm{B}_{12}$.

Установлено, что углеродные сорбенты из лигнина древесины пихты способны поглощать маркерные вещества из растворов с различными значениями $\mathrm{pH}$, моделирующих среды желудка и кишечника. Показано, что наиболее эффективная сорбция метиленового синего достигается из щелочного раствора, моделирующего условия среды кишечника, а витамина $\mathrm{B}_{12}-$ из кислого раствора, моделирующего условия среды желудка. Установлено, что исследуемые сорбенты обладают способностью быстро сорбироватью метиленовый синий независимо от рН раствора (более $87,5 \%$ в течение 5 мин).

Определено, что максимальная сорбция метиленового синего углеродными сорбентами из лигнина пихты составляет 1074,4 , а витамина $\mathrm{B}_{12}-188,7$ мг/г. По сорбции витамина $\mathrm{B}_{12}$ углеродные сорбенты из лигнина древесины пихты превосходят промышленные активированные угли медицинского назначения в 4,2 раза, а по сорбции метиленового синего - в 3,1 раза. Полученные результаты указывают на потенциальную возможность применения углеродных сорбентов из органосольвентного лигнина древесины пихты в качестве эффективных энтеросорбентов в целях удаления токсинов различной природы.

\section{Список литературы}

1. Морозов А.С., Бессонов И.В., Нуждина А.В., Писарев В.М. Сорбенты для экстракорпорального удаления токсических веществ и молекул с нежелательной биологической активностью (обзор). Общая реаниматология 2016. T. 12(6), C. 82-107. [Morozov A.S., Bessonov I.V., Nuzhdina A.V., Pisarev V.M. Sorbents for extracorporal removal of toxic substances and molecules with adverse biological activity (Review). General Reanimatology 2016. Vol. 12(6), P. 82-107. (in Russ.)]

2. Sokolov M.N., Kuzminova A.M., Kanatbaev S.G. Enterosorption as a method of detoxification therapy in animal and birds. Modern Science 2017. No. 2, P. 57-59. 
3. Chy Gye Moon, Jund Ched Kyu, Kim Hoi Yun, Ha Zi Hee, Kim Jong Hyun. Effects of bamboo charcoal and bamboo vinegar as antibiotic alternatives on growth, performance, immune responses and fecal microflora population in fattening pigs. Animal Science Journal 2013. Vol. 84(2), P. $113-120$.

4. Богданович Н.И., Короткий В.П., Великанов В.И., Носков Д.К. Переработка низкосортной и мелкотоварной древесины в энтеросорбенты для сельского хозяйства методом совмещенного процесса карбонизации - активации на модульных установках в полевых условиях. Известия вузов. Лесной журнал 2010. № 4, С. 126-131. [Bogdanovich N.I., Korotky V.P., Velikanov V.I., Noskov D.K. Processing of low-grade and small merchantable wood into enterosorbents for agriculture by method of concurrent process of carbonation - activation on modular installations in field conditions. Bulletin of HES. Forest Journal 2010. No. 4, P. 126-131. (in Russ.)]

5. Lavrenev A.V., Pyanova L.G., Sedanova A.V., Luzyanina L.S. Nanostructured carbon sorbent impregnated with botulin. Solid Fuel Chemistry 2015. Vol. 49(1), P. 7-13.

6. Суровикин В.Ф., Пьянова Л.Г., Лузянина Л.С., Долгих В.Т. Углеродные гемо- и энтеросорбенты на основе нанодисперсных углерод-углеродных материалов использование их в медицине при критических состояниях. Эфферентная терапия 2008. Т 14(1-2), С. 4-8. [Surovikin V.F., Pyanova L.G., Luzyanina L.S., Dolgix V.T. Carbon hemo- and enterosorbents based on nanodispersed carbon-carbon materials and its application in medicine at critical conditions. Efferental Therapy 2008. Vol. 14 (1-2), P. 4-8. (in Russ.)]

7. Гарынцева Н.В., Судакова И.Г., Кузнецов Б.Н. Свойства энтеросорбентов, полученных из уксуснокислотных лигнинов древесины пихты, осины и березы. Журнал Сибирского Федерального Университета. Химия 2011. Т. 4(2), С. 121-126. [Garyntseva N.V., Sudakova I.G., Kuznetsov B.N. Properties of enterosorbent sobtainedfromaceticacidlignins of Abies, Aspenand Birchwood. Journal of Siberian federal University. Chemistry 2011. Vol. 4(2), P. 121-126. (in Russ.)]

8. Lee J.B., Yamagishi C., Hayashi K., Hayashi T. Antiviral and immunistimulating effects of lignin-carbohydrate-protein complexes from Pimpinellaanisum. Bioscience. Biotechnology. Biochemistry 2011. Vol. 75(3), Р. 459-465.

9. Иванов И.П., Микова Н.М., Лутошкин М.А., Чесноков Н.В., Кузнецов Б.Н. Изучение строения и свойств нанопористых углеродных материалов, полученных термощелочной активацией лигнинов древесины пихты. Журнал сибирского федерального университета. Химия 2017. T. 10(3), C 390-400. [Ivanov I.P., Mikova N.M., Lutoshkin M.A., Chesnokov N.V., Kuznetsov B.N. The study of structure and properties of nanoporous carbon materials obtained by alkaline thermal activation of lignin of Fir wood. Journal of Siberian Federal University. Chemistry 2017. Vol. 10(3), P. 390-400. (in Russ.)]

10. Энтеросорбция, под ред. Н.А. Белякова. Ленинград: Центр сорбционных технологий, 1991. 328 c. [Enterosorption/Editted by Belyakov N.A. Leningrad: Center of sorption technology, 1991. 328 p. (in Russ.)]

11. Onishchenko D., Reva V. Sorption properties of carbon - base materials from sphagnum moss. Chemistry and Technology of Fuels oil 2013. Vol. 49(2), P. 93-98.

12. Патент 2377179 РФ. Мухин В.М., Жуков Д.С., Зубова И.Д., Чебыкин В.В., Чумаков Д.С., Соловьев С.М., Курганов Р.П. Углеродный адсорбент, способ получения и установка для его осуществления. Опубл. 27.12.2009. [Patent 2377179 RU. Muxin V.M., Gukov D.S., Zubov I.D., 
Chebykin V.V., Chumakov D.S., Solovev S.M., Kurganov R.P. Carbon adsorbent, method of its preparations and installation for him obtaining. Publ. Date 27.12.2009. (in Russ.)]

13. Reshetnikov V.I. Evaluation of the adsorption capacity of enterosorbents and related medicinal preparations. Pharmaceutical Chemistry Journal 2003. Vol. 37(5), P. 246-251.

14. Markelov D.A., Nitsak O.V., Gerashenko T.T. Comparative study of the adsorption activity of medicinal sorbents. Pharmaceutical Chemistry Journal 2008. Vol. 42(7), P. 405-408.

15. Морозова А.А., Лыга Л.К., Ермоленко И.Н. Оролимикро- и мезопор волокнистых активных углей в сорбции веществ маркеров из водных сред. Журнал прикладной химии 1989. № 12. C. 2777-2781. [Morozova A.A., Lyga L.K., Ermolenko I.N. About rule of micro- and mezopores fiber active carbon in sorption of marker substances from water medium. Journal of Applied Chemistry 1989. No. 12. P. 2777-2781. (in Russ.)]

16. Ланин С.Н., Рычкова С.А., Виноградов А.Е., Вирясов М.Б., Востров И.А., Шаталов И.А. Сорбция водорастворимых витаминов на сорбентах различной природы. Сорбиионные и хроматографические проиессы 2015. T. 15(2), C. 179-195. [Lanin S.N., Rychkova S.A., Vinogradov A.E., Viryasov M.B., Vostrov I.A., Shatalov I.A. Sorption of water - soluble vitamins in various sorbents. Sorption and Chromatographic Processes 2015. Vol. 15(2), P. 179-195. (in Russ.)]

17. Михайлов О.В. Желатин - иммобилизованные металлокомплексы. М.: Научный мир, 2004. 236 c. [Michailov O.V. Gelatine - immobilized metalcomplexes. M.: Nauchyimir, 2004. 236 p. (inRuss.)]

18. Адсорбиия из растворов на поверхности твердых тел: пер. с англ., под ред. Г. Парфита, К. Рочестера. М.: Мир, 1986. 488 с. [Adsorption from solution at the solid/liquid interface: trans. from English, Editted by Parfitt G.D., Rochester C.H.M: Mir, 1986. 488 p. (in Russ.)] 